\title{
Let Women Take the Lead: Insights from the UK Defense Industry
}

\author{
Andri Georgiadou, Equality Inclusion Diversity Center, Cyprus \\ Beverly Dawn Metcalfe, USEK, Lebanon \\ Claire Rimington, University of Hertfordshire, UK
}

\section{Introduction}

We discuss how gender diversity in the workplace is managed (or not) within a non-traditional environment, specifically a UK defense company, aiming to gain an understanding of the impact on female employees. We argue that there are still remnants of bias - both conscious and unconscious - within the workplace, and some of the female participants felt that discrimination is embedded in the corporate culture. Our study revealed that there are currently no female role models within the senior ranks; and few women had progressed into middle management. We position the study within debates around diversity and inclusion and human capacity development in the UK defense sector in general, and specifically the armed forces. We also show how issues of equality are addressed in diverse ways, through legislation and gender quotas, and emphasize why achieving and safeguarding gender equality is important to practicing managers.

\section{Women Limited to Stereotypical Roles within the Organization}

In the UK defense industry, the Ministry of Defense is addressing inclusion by mainstreaming gender policy development processes and is committed to undertaking an Equality Analysis every year. In 2010, the Equality Act required all public institutions to have in place diversity strategies and be aligned with growing the numbers of previously marginalized groups to represent the current population of the UK. There is currently a target to increase female personnel to $15 \%$ of the total armed forces (army, marines, RAF) intake by 2020 .

This poses a serious challenge to the paternalistic environment in the UK defense sector organization, which is the focus of the study. Although women are rated better than men on key leadership capabilities, only $4.9 \%$ of Fortune 500 CEOs and $2 \%$ of S\&P 500 CEOs are women (Zenger \& Folkman, 2019), which is also true in the defense industry and especially in the company where our study was conducted. There are only three women currently in executive positions and there is no female representation at the board level, despite the company's rhetoric to acknowledge that "a diverse workforce frequently drives change and innovation which is of paramount importance within the company" (Company's public statement).

Gender stereotyping can produce career-hindering judgments with gender bias to have been acknowledged to have had an impact on the lack of upward mobility of women within the organization and the dearth of women in senior management positions.

This results in women being underrepresented in decision-making positions in supply defense contracts. Beyond differences in contexts, organizational and national (Georgiadou, Gonzalez Perez, \& Olivas Lujan, 2019), this common phenomenon reflects the masculinization of governance in the defense industry, resulting from a long record of male-dominated knowledge production. Armed forces and the defense sector are largely staffed by men and exploring decision making and governance 
from a gender perspective can provide insights into change efforts to support inclusive sustainable development.

\section{Women's Feelings on Being Valued (or Not) by Their Organizations}

At the macro level, despite an abundance of legislation and gender quotas which promote equality in the workplace, pay and promotion prospects for female professionals in the defense industry are inferior to those of men. The careers of women in this field are not only mediated, but also constrained by policies and the status quo as well as other inter-related aspects such as age and/or migrant status. It is also notable that meso level factors, including leadership opportunities and experiences, career guidance, and family influences, can have subsequent implications for micro level factors. Access to "social capital," which is the aggregate of the resources linked to membership in a group, is frequently the privilege of the dominant, often white male group.

In gathering evidence about heterogeneous female experiences of gender equality, we draw on the reflections of 406 female employees working at a UK defense company. The mixed-method case-study sample consists of employees at various levels and of varied demographic characteristics, thus offering insights into diverse responses. The findings of our study (established through exposing the qualitative data to a grounded analysis), suggest that having a gender quota could be tricky, which runs counter to current national defense staffing plans to establish quotas to appoint more women. Employees stated that, even though they feel safe when their company is publicly demonstrating that they are aiming to recruit more females in the workplace, the management needs to be careful not to lead into a "she only got the job because she is a female" thought loop. Female employees generally agreed that hire and promotion based on merit was more important than based on the obligation to improve the gender statistics. Conversely, female employees emphasized the importance of aligning the gender distribution of people with engineering qualifications with the corresponding representation in the workplace. Despite women's engineering qualifications, their roles were often in gender stereotypical functions. Female employees further argued that policies for hiring and promotion procedures needed to be transparent and fair and not be viewed as management simply meeting gender quotas and pushing equality agendas. Further, women themselves felt they could not openly support gender equality as this would undermine their professional competence and identity. This resistance to 'gender aware' policy making again runs counter to national defense policies to mainstream diversity and inclusion (Ministry of Defence, 2018).

We conclude from these findings that women often feel they are not listened to or valued even when they have defense engineering qualifications. In fact, they feel that the company is comfortable with women in certain sectors, e.g., Human Resources, Major Equipment Purchasing, Business Support Office, but not as comfortable in technical roles. Hence, women in technical roles, are likely to fall out of the ranks as they ascend the corporate ladder. More broadly, articulating a gender unaware philosophy, we can see that for women to climb the ladder in this company, and the defense sector in general, they need self-reliance, as there is a lack of drive on the part of the company to ensure that the board and senior level positions are represented equally by women.

\section{Gender Equity Issues within the Organizaltion}

The reality of male-dominated industries requires women to assert themselves and advocate their professional value and, where appropriate, commit to the "silencing" of male-based development strategies. This stems from the plethora of challenges women working in these industries face, including pervasive stereotypes, such as that of the caring mother or office housekeeper. In this section, we discuss the obstacles women face working in the male-dominated workplace culture, as women are often perceived as less technically competent.

Drawing on evidence from quantitative research surveys of the same sample, we find that women are being caught in a territorial workplace, with ongoing struggles for power, colleagues leaving because of their family responsibilities, and the perception that they are still being treated differently because they are women. Female employees who had left the engineering company cited lack of confidence, intimidation, and isolation as the rationale behind their decisions to leave. Our evidence suggests that a lack of role models and mentors is also a key factor in female employees' feeling of isolation. If there had been mentoring programs in place that connected female professionals, levels of retention would have possibly been higher. Furthermore, these departures often reflect frustration among women about the challenges of a male-dominated organizational culture where they feel they have to prove their competence ad nauseam.

Female employees felt that there were fewer opportunities for them to step into more senior positions due to gender stereotypes, with some of them considering leaving their current job role because of barriers to career progression. The company had supported the development of a women's network, and many felt the network was ineffective as it was an informal grouping. For example, female employees argued that previously asking to work from home was often associated with the responsibilities of care and motherhood. By contrast, requests from men to work from home were assumed to imply a need for more space for them to be able to concentrate and hence produce more. 
There is therefore a culture that represents "gender conscious unconsciousness," that is, showing awareness of gender disparities, but not articulating this openly (Metcalfe, 2008). That puts more pressure on females when working from home to go over and above to make a statement that they are indeed working, as they are often perceived by the management to be less likely to work extended work days.

In light of this, the pressure of being in the minority could be exercised as an extra pressure, creating a feeling that a woman have been argued as powerful stakeholders in guiding foreign direct investment, and in diffusing assumptions about gender practices and gendered global norms, there are certain international business sectors that will remain strongly influenced by government, the defense industry being one.

This article re-examines the clear under-representation of women in defense industry key-positions, including management. Though participants in our research were both interested in and capable of accessing the ranks of power, they were unable to break the glass-ceiling stemming from prejudiced stereotypes. Ignoring gender inequality issues results in costs measured in time, money and effectiveness. Arguing for gender equality in the workplace is vital to a healthy and growing defense sector: harnessing people's skills and talents regardless of their gender or race can turn the organization into a strong rival. In fact, the economic case for within a male dominated environment has to work harder, as any likely failure or lack of achievement will have an impact on the reputation and/or perceived value of all women within the workforce. There seems to be a background awareness that female employees need not to fail, as this could reflect badly on the small female population.

\section{What Can Be Done?}

In July 2019, General Electric (GE) Company announced a gender diversity target ${ }^{1}$ : a goal to hire 20,000 women in engineering roles by the year 2020. This was a significant stake to stress GE's position on the business benefits of gender equality. Similarly, Kathy Warden's ascension in the summer of 2019, implies that four of the five largest defense firms in the United States - Lockheed Martin, Boeing's Defense Arm, Northrop and General Dynamics - will be led by women. These initiatives are a forerunner of solutions to frame gender equality and international business in the context of talent and merit.

Our study highlights the engrained stereotypes about women being able to take on defense engineering careers and of organizational barriers to career advancement. Why is this study important in advancing understanding of international business and gender and diversity issues? The defense sector is a growing field of inquiry for international business as international relations and relationships are stressing increased commitment to nationalist agendas, and likewise associated capacity building of defense sectors. While multinational corporations (MNCs) gender equality in the EU estimates that by 2050, improving gender equality would lead to an increase in EU (GDP) per capita by 6.1 to $9.6 \%$, which amounts to $€ 1.95$ to $€ 3.15$ trillion (European Institute for Gender Equality, 2017).

This raises the important question of how do organizational and governmental stakeholders shape dialogues of gender and diversity in international business and the defense sector? How are these dialogues translated and understood by international relations partners?

In the UK defense sector, organizations, together with all public administration departments, are required by law to put in place diversity and inclusion policies, and measures to tackle exclusion, as outlined in the 2010 Equality legislation. The language of diversity and inclusion is now part of the legislative mosaic and wholly legitimized in government policy planning. The MOD states that "operational effectiveness depends on cohesion and teamwork, which are enhanced by treating everyone fairly, with dignity and respect" (Ministry of Defence, 2018 , p. 15). While operation effectiveness is stressed, the legislation emphasizes the importance of inclusion as an organization and society ethic. This moves the debate way beyond the ideas that diversity is just good business practice. The debate about quotas remains complex, and in the UK context quotas are advocated in the public sector, but not so in the private context. How will the international business defense sector respond to a growing concern about women's inclusion, with legislation that advocates quotas? 
Our findings could be useful for policymakers and managers alike. From a practical point of view, the results initiate the discussion on how the level of gender equality awareness and approach in the defense industry could be used as a predictor of leadership effectiveness, job satisfaction, and work-life balance; knowledge which could potentially translate into greater synergies between diversity and human resource managers and defense policymakers. At the same time, the findings also point toward the possible "signaling" power that gender equality cultures have for current and potentially future employees: a firm with a demonstrable interest in promoting and establishing gender equality is likely to pay greater attention to the employees' well-being as well. Knowing that it costs British businesses four billion pounds each year to replace staff members (Unum, 2014), our findings could carry considerable importance to firms seeking to reduce turnover.

A way forward is to convince the international defense industry of the value of equality and inclusion in their governance defense planning. Importantly, senior business leaders need to appreciate the governance policies of the defense sectors in different countries. We have illustrated that the UK is addressing diversity and inclusion in different ways. Consequently, there is a need for international business leaders to appreciate the myriad of ways in which gender diversity issues can be addressed and challenged by corporations in the global economy.

\section{References}

European Institute for Gender Equality. 2017. Economic Benefits of Gender Equality in the European Union: Overall economic impacts of gender equality. Vilnius: European Institute for Gender Equality. https://eige.europa.eu/gender-mainstreaming/policy-areas/ economic-and-financial-affairs/economic-benefits-gender-equality. Accessed 13 August 2019.

Georgiadou, A., Gonzalez-Perez, M.-A., \& Olivas-Lujan, M. 2019. Diversity within Diversity Management: Country-Based Perspectives Vol: 21. Bingley, UK: Emerald Publishing Limited.

Metcalfe, B. D. 2008. A feminist poststructuralist analysis of HRD: Why bodies, power and reflexivity matter. Human Resource Development International, 11 (5): 447-463.

Ministry of Defence. 2018. A Force for Inclusion: Defence Diversity and Inclusion Strategy 2018 - 2030. MOD. https://assets.publishing. service.gov.uk/government/uploads/system/uploads/attachment data/file/746911/20180806-MOD DI Plan A4 v14 Final-U. pdf. Accessed 13 August 2019.

Unum. 2014. The Cost of Brain Drain: Understanding the Financial Impact of Staff Turnover February 2014. Oxford, UK: Oxford Economics.

Zenger, J., \& Folkman, J. 2019. Women score higher than men in most leadership skills. Harvard Business Review (online), June 25.

\section{Endnote}

1 https://fairygodboss.com/articles/ge-hopes-new-goals-will-narrowstem-gender-gap

Dr. Andri Georgiadou (equidy@andrigeorgiadou.com) is the Director of the Equality Inclusion and Diversity (EQUIDY) Center in Cyprus. Her research focuses on equality, diversity and inclusion at work from relational and interdisciplinary perspectives.

Professor Beverly Dawn Metcalfe (metcalfebd@yahoo.co.uk) spent most of her career in the Global Development Institute, University of Manchester before moving to the Middle East 2017. She currently works in Saudi Arabia and Lebanon and her work is internationally recognized for translating social science into work policies and practices that promote sustainable business, especially staff development and capability in the UK and Middle East,

Ms. Claire Rimington (rimingtonclaire@gmail.com) is a contract management professional with a strong research interest on practices that effectively promote gender equality in the workplace, and especially the STEM industry. 